\title{
Skeletally Modified Polyamide Flame Retardant Coatings
}

\author{
J. Sheeba Vinolia, D. Duraibabu, S. Aparna, S. Ananda Kumar* \\ Department of Chemistry, Anna University, Chennai, India \\ Email: sri anand 72@yahoo.com
}

Received 6 July 2014; revised 26 August 2014; accepted 30 September 2014

Copyright (C) 2014 by authors and OALib.

This work is licensed under the Creative Commons Attribution International License (CC BY). http://creativecommons.org/licenses/by/4.0/

(c) † Open Access

\begin{abstract}
The use of polyamide coatings for electrical applications is restricted mainly because of its inadequate flame retardant behaviour. In order to improve its flame retardant behaviour, polyamide is modified by incorporating phosphorus moiety in its backbone. The structure of the phosphorus and poly amide was confirmed by infrared spectroscopy (FT-IR), NMR, thermo gravimetric analysis (TGA), differential scanning calorimetry (DSC), UL-94 vertical burning tests and char residue tests. From the results obtained, we observe that the incorporation of phosphorus into the polyamide enhances its thermal stability and flame retardancy.
\end{abstract}

Keywords

Flame-Retardant Coatings, Polyamide-Phosphorus, Thermal Stability, UL-94

Subject Areas: Green Chemistry, High Polymer Chemistry, Organic Chemistry, Organic Polymer Materials

\section{Introduction}

Nylon (polyamide) was invented in 1928 by Wallace Carothers (DuPont) and it is considered to be the first engineering thermoplastic. It is one of many hetero-chain thermoplastics, which have atoms other than $\mathrm{C}$ in the chain. Nylon is created when a condensation reaction occurs between amino acids, dibasic acids and diamines.

Nylon is commonly used in the production of tire cords, rope, belts, filter cloths, sports equipment and bristles. It is particularly useful when machined into bearings, gears, rollers and thread guides. Though polyamide has good mechanical properties such as tensile strength, flexural strength and impact strength, its use in electrical industry has been restricted due to its inferior flame retardancy [1]-[4].

Polyamide can be made flame retardant either by the use of flame-retardant curatives or by incorporating reactive flame-retardant additives in the polymer backbone. Recently, researchers have mainly focused on the

*Corresponding author.

How to cite this paper: Vinolia, J.S., Duraibabu, D., Aparna, S. and Kumar, S.A. (2014) Skeletally Modified Polyamide Flame Retardant Coatings. Open Access Library Journal, 1: e966. http://dx.doi.org/10.4236/oalib.1100966 
latter because the flame-retardants when chemically incorporated into the polymer structure result in advantages such as more stability and the less gas emission during either high temperature processing or burning. Simultaneously, the reactive approach can minimize negative impact upon physical and mechanical properties of the polymer. Phosphorus containing flame-retardants are preferably chosen, as they are more eco-friendly than the halogen containing ones [5]-[18].

Commercial polyamide 6,6 was prepared by poly-condensation reaction of hexamethylene diamine and adipic acid [1]. In this work, phosphorus is incorporated into the backbone of the polyamide by reacting phosphorus diamine with adipic acid in order to increase the flame retardant behaviour. It is characterized by means of IR, TGA, DSC and flame retardancy tests to evaluate its suitability for electrical applications.

\section{Experimental}

\subsection{Materials}

Triphenyl phosphine oxide and Tin(II) chloride anhydrous were purchased from Alfa-Aesar (USA). Sulfuric acid, nitric acid, chloroform, ethanol, hydrochloric acid were purchased from SRL (India). Adipic acid was purchased from Alfa chem (USA).

\subsection{Preparation of Phosphorus Diamine}

Phosphorus diamine was synthesized according to the reported procedure [19]. The steps involved in the synthesis are shown in Scheme 1. Triphenyl phosphine oxide (27.8 g) was placed in a $500 \mathrm{ml}$ round-bottomed flask equipped with stirrer and nitrogen atmosphere and $200 \mathrm{ml}$ of $96 \%$ sulfuric acid was added. The reactant was dissolved and the reaction system was cooled to $-5^{\circ} \mathrm{C}$ using freezing mixture. A solution of $14.5 \mathrm{~g}$ of fuming nitric acid in $100 \mathrm{ml}$ of sulfuric acid was added drop wise over a period of $2 \mathrm{hrs}$. The reaction system was kept at room temperature for another 8 hrs. The reaction solution was hydrolyzed over 2 litres of ice. After the ice melted, the mixture was extracted with chloroform and washed with sodium bicarbonate aqueous solution until neutral $\mathrm{pH}$. The solvent was removed and the solid residue was recrystallised from absolute ethanol. Bis (3-nitrophenyl) phenyl phosphine oxide was obtained. Then it was placed in a $1000 \mathrm{ml}$ round bottom flask with $180 \mathrm{~g}$ of powdered anhydrous Tin(II) chloride. A solution of $200 \mathrm{ml}$ fuming hydrochloric acid in $400 \mathrm{ml}$ ethanol was introduced into the flask. The reaction mixture was stirred at room temperature for 5 hrs. The solution was concentrated and then neutralized with $25 \% \mathrm{NaOH}$ aqueous solution. The obtained solution was extracted with chloroform and concentrated under reduced pressure. The solid obtained was recrystallised from dichloromethane to give the pure product.
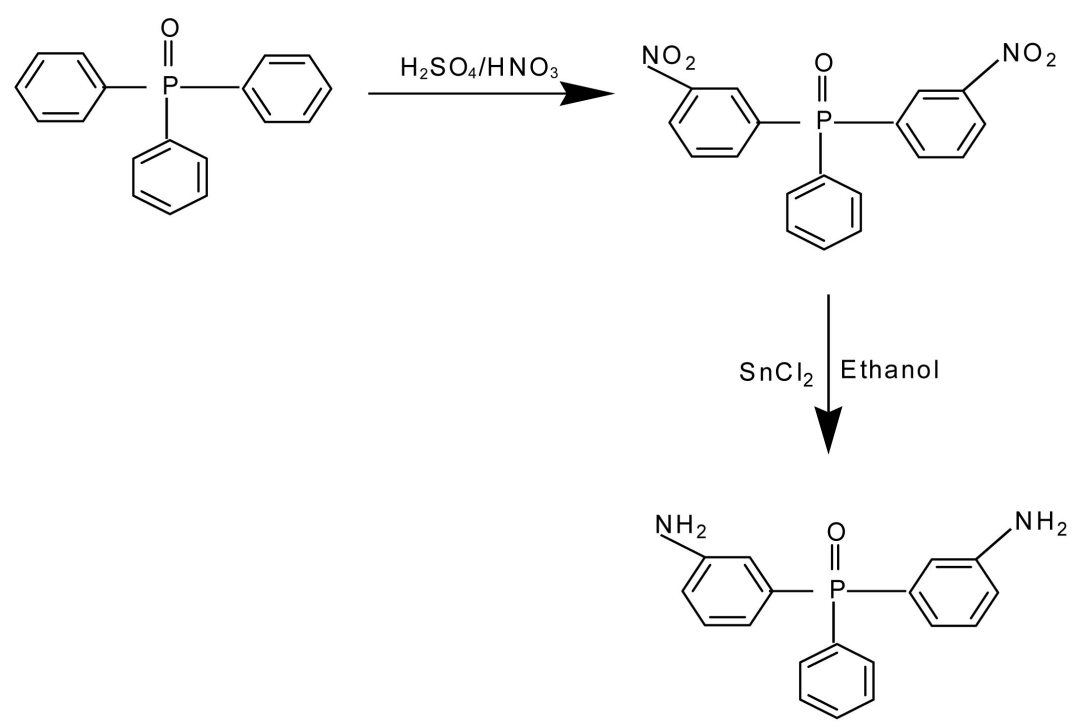

Scheme 1. Synthesis of phosphorus diamine. 


\subsection{Synthesis of Polyamide 6,6}

The phosphorus diamine obtained is made to react with the adipic acid by a polycondensation reaction to obtain polyamide with phosphorus moiety incorporated in the backbone [20]. The reaction is depicted in Scheme 2. Equal amounts of adipic acid and phosphorus diamine are taken and dissolved in a suitable solvent and stirring is continued until product is formed.

Then it is filtered using suitable solvent with the elimination of water molecules and subjected to drying and the product obtained in the powder form is weighed. Thus modified polyamide 6,6 is prepared subjected to various characterizations such as TGA, DSC and flame retardancy tests.

\subsection{Characterization}

The structure of polyamide was determined by IR, which was performed on Perkin-Elmer 781 infrared spectrometer using $\mathrm{KBr}$ pellets for solid samples. Glass transition temperature (Tg) of the samples was determined using DSC 2910 (TA Instruments USA) in the temperature range of room temperature to $200^{\circ} \mathrm{C}$ at a heating rate of $10^{\circ} \mathrm{C} \mathrm{min}{ }^{-1}$. Thermal gravimetric analysis (TGA) was carried out using Thermal analyst 2000 (TA Instruments USA) at a heating rate of $10^{\circ} \mathrm{C} \mathrm{min}^{-1}$ in the temperature range from room temperature to $900^{\circ} \mathrm{C}$. UL94 vertical burning tests were carried out for flame retardancy.

\section{Results and Discussions}

\subsection{Spectral Analysis}

Phosphorus diamine was synthesized and the structure was determined by IR spectrum. Figure 1 shows the IR spectrum of phosphorus diamine. The peak at $1205.48 \mathrm{~cm}^{-1}$ indicates the formation of P-Ph. The absorption peak for $\mathrm{P}=\mathrm{O}$ and $\mathrm{NH}_{2}$ were observed at $1452.05 \mathrm{~cm}^{-1}$ and $3473.97 \mathrm{~cm}^{-1}$ respectively [10].

Polyamide modified with phosphorus backbone was synthesized and structure was determined using IR spectrum depicted in Figure 2. The presence of $\mathrm{P}=0$ is observed in $1197.84 \mathrm{~cm}^{-1}$, -NH stretching was found to be $3558.92 \mathrm{~cm}^{-1}$ and the absorption peak of $-\mathrm{COOH}$ was found to be $1703.78 \mathrm{~cm}^{-1}$. This confirms the presence of polyamide.

\subsection{Thermal Gravimetric Analysis (TGA)}

TGA studies of polyamide with phosphorus backbone was carried out to assess its thermal stability and char protecting nature. The thermogram of phosphorus modified polyamide as seen in Figure 3. Exhibits a double degradation pattern involving initial degradation at a temperature $94.2^{\circ} \mathrm{C}$ followed by a second degradation at $452^{\circ} \mathrm{C}$ respectively. The initial degradation at $94.2^{\circ} \mathrm{C}$ may be attributed to the decomposition of phosphate group, which forms a self healing layer that prevents further degradation of the material. Then second degradation takes place at $452^{\circ} \mathrm{C}$ indicating the thermal degradation temperature of the material. The comparison table of Glass Transition temperature (Tg) is given in Table 1. Furthermore, the char residue of phosphorus modified polyamide was found to be (60.85\%) on the higher side, indicating the superior flame retardant behaviour of this material than nylon and other phosphorus based compounds reported by Van Krevlan. This excellent flame retardent nature of this material may be due to char protecting nature of the phosphorus moiety [21].

\subsection{UL-94 Flame Retardancy Tests}

Unmodified polyamide and phosphorus modified polyamide samples prepared as per UL-94 standard were tested by UL-94 vertical burning test [22] to evaluate their flame retardancy. The results are depicted in Table 2. The ratings are given for samples by subjecting them to vertical burning for 30 secs and noting down the time taken for each sample to sustain burning even after removing them from the flame. It is observed that phosphorus modified polyamide exhibits better flame retardant behaviour (V0 rating) than unmodified polyamide (V2 rating) indicating the superior char protecting nature of phosphorus.

\subsection{Limited Oxygen Index vs Char Residue}

Van Krevelan [23] proposed a correlation between char residue and limited oxygen index as seen in Figure 4. From this correlation, the limiting oxygen index value and flame retarding behaviour of materials can be 


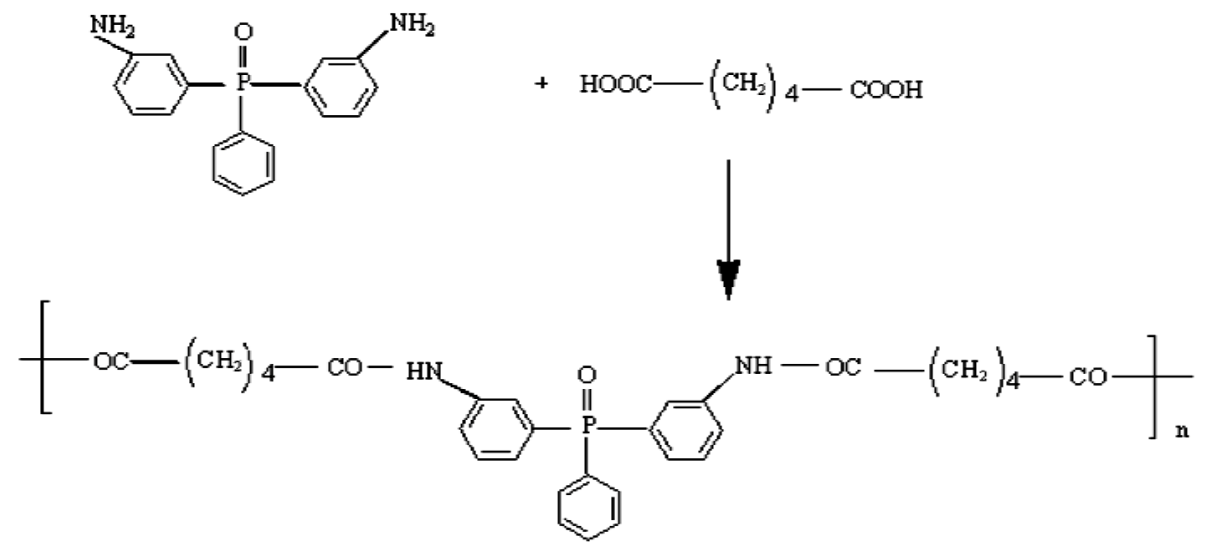

Scheme 2. Synthesis of modified polyamide.

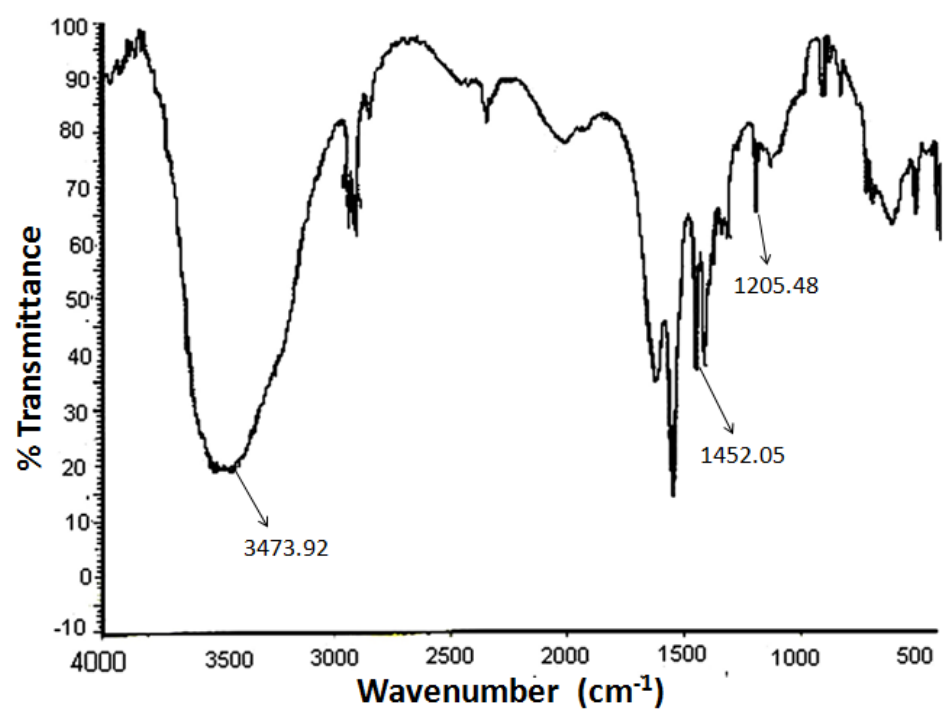

Figure 1. IR spectrum of phosphorus diamine.

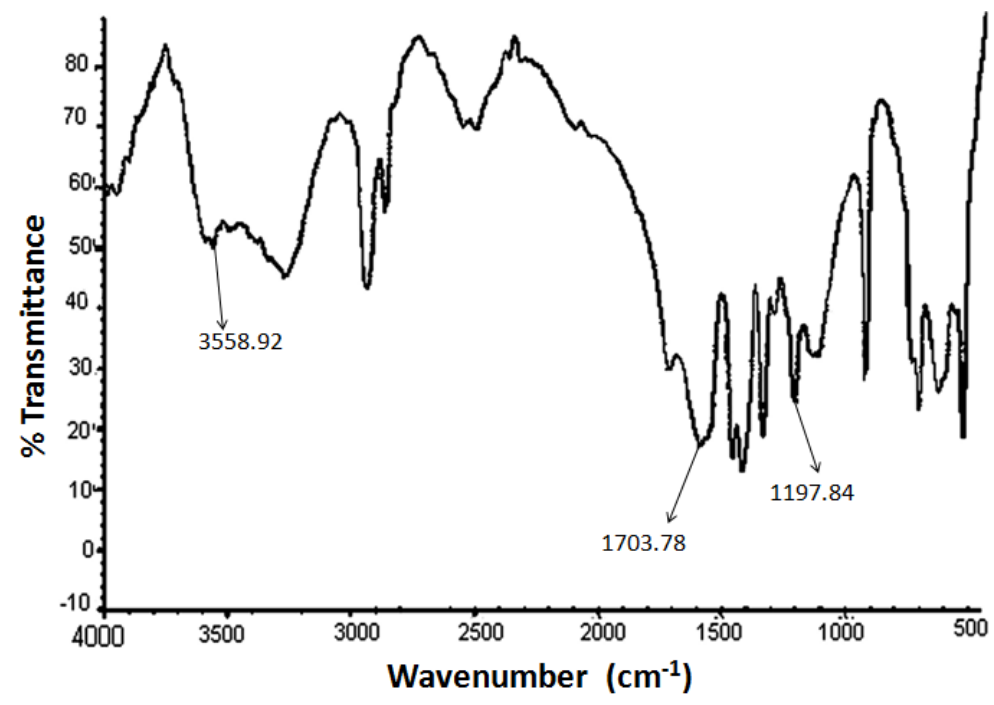

Figure 2. IR spectrum of modified polyamide. 


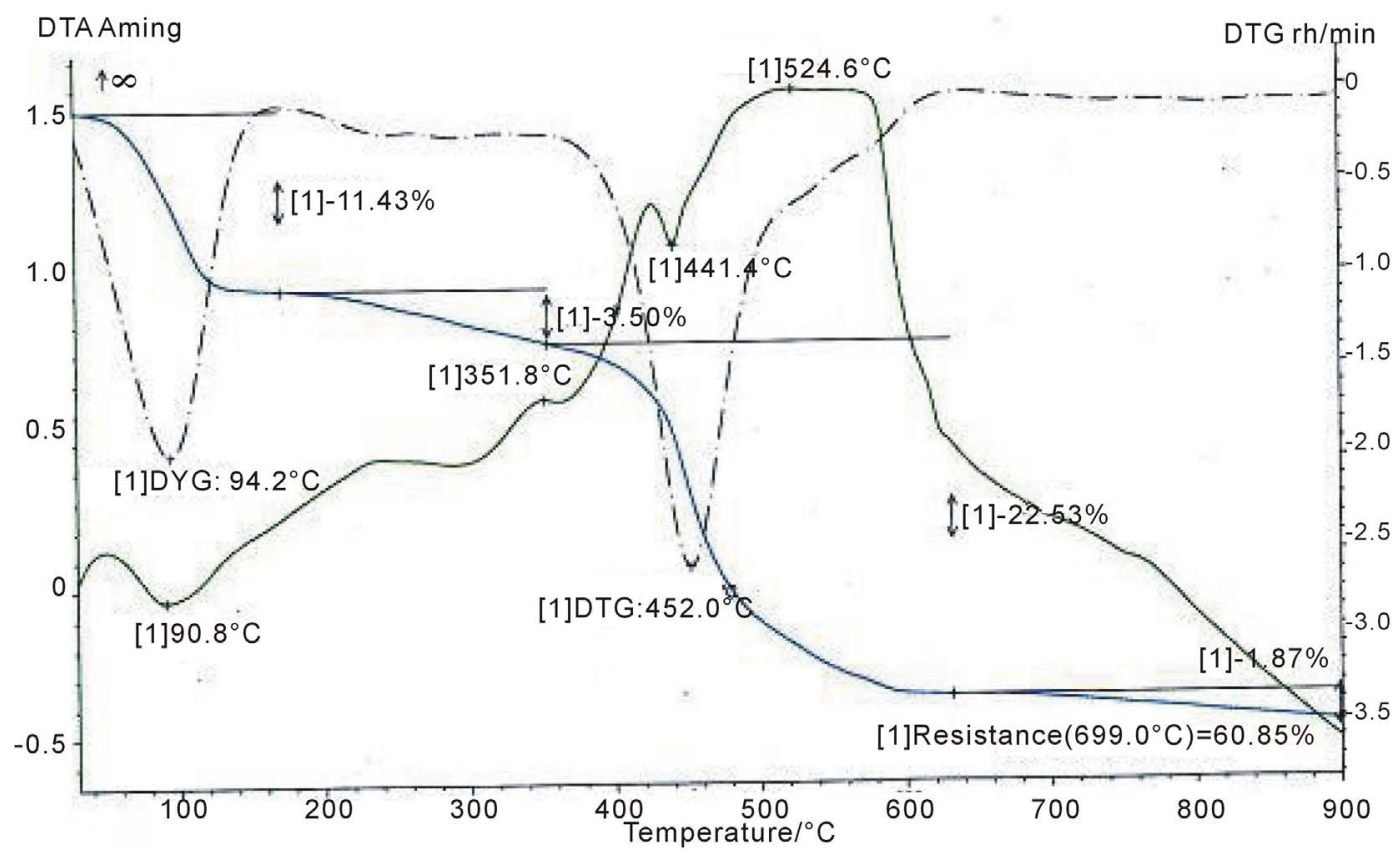

Figure 3. TGA analysis.

Table 1. Comparison of “Tg” values.

\begin{tabular}{cc}
\hline Material & $\mathrm{Tg}$ \\
\hline Polyamide (commercial) & $47^{\circ} \mathrm{C}-50^{\circ} \mathrm{C}$ \\
Polyamide (with phosphorus backbone) & $36.7^{\circ} \mathrm{C}$ \\
\hline
\end{tabular}

Table 2. UL-94 vertical burning tests ratings.

\begin{tabular}{cccc} 
Material & Time & Rating & Remarks \\
\hline Polyamide (commercial) & $30 \mathrm{sec}$ & V2 & Flammable \\
Polyamide (with phosphorus backbone) & $10 \mathrm{sec}$ & V0 & Flame retardant \\
\hline
\end{tabular}

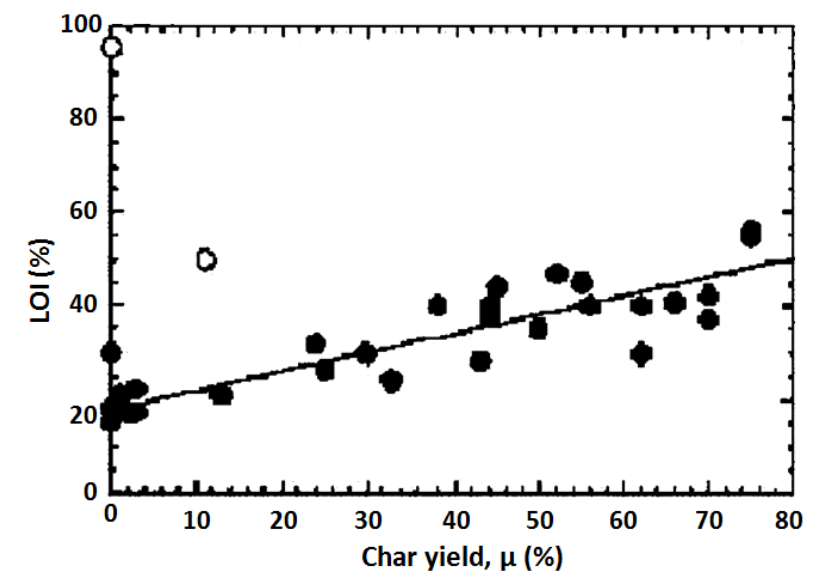

Figure 4. Correlation between char residue and limited oxygen index.

determined. From the TGA data the char residue of phosphorus modified polyamide is found and correspondingly the limiting oxygen index was reported to be 42 . Higher the limited oxygen index value higher will be the flame retardancy. 
Table 3. Determination of limited oxygen index.

\begin{tabular}{cc}
\hline Material & Limited oxygen index (LOI) \\
\hline Polyamide (commercial) & $18-20$ \\
Polyamide (with phosphorus backbone) & 42 \\
\hline
\end{tabular}

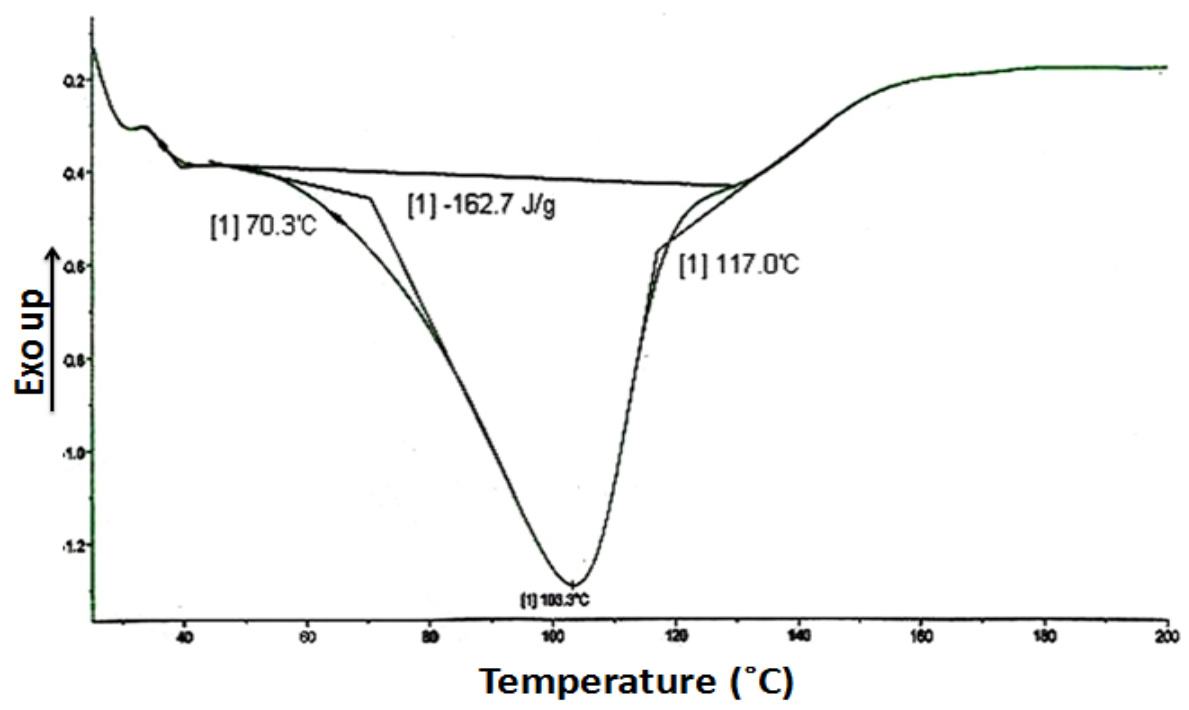

Figure 5. DSC analysis.

From the results (Table 3), it is concluded that the phosphorus-modified polyamide has superior flame retardancy than unmodified polyamide and materials that are currently used as flame-retardants.

\subsection{DSC Analysis}

DSC thermograms of unmodified nylon and phosphorus modified polyamide are depicted in Figure 5. From the thermograms, we observe that phosphorus modified polyamide exhibits lower Tg value than the unmodified polyamide (Table 3). This decrease in Tg value may be attributed to the presence of phosphorus which acts as a internal plasticizer [24].

\section{Conclusion}

Polyamide is made from flame retardant coating by reacting phosphorus diamine with adipic acid to get phosphorus modified polyamide. Spectral analysis was done using IR. Thermal stability, char nature, flame retardancy and Tg were evaluated by TGA, UL-94 vertical burning tests and DSC studies respectively. From the results, it can be seen that phosphorus modified polyamide has better thermal stability and flame retardancy. The data resulted from various studies support this observation. Hence, it is concluded that phosphorus-modified polyamide having improved thermal stability and flame retardancy may be used as flame retardant coating in electrical applications for better performance.

\section{Acknowledgements}

One of the authors S. Ananda Kumar is grateful to DST (Department of Science and Technology, INDIA, Grant No. SR/S1/PC-11/2006 dtd.06.09.2006) for financial assistance to carry out this work. The authors are thankful to Anna University for providing necessary facility to carry out this work.

\section{References}

[1] Brydson, J.A. (1999) Plastic Materials. 7th Edition, Butterworth-Heinemann, Oxford.

[2] Nelson, W.E. (1976) Nylon Plastics Technology. Newnes-Butterworths, London. 
[3] Stille, J.K. (1962) Introduction to Polymer Chemistry. Wiley, Hoboken.

[4] Naidu, M.S. (1999) High Voltage Engineering. 4th Edition, McGraw Hill, New York.

[5] Buckingham, M.R., Lindsay, A.J., Stevenson, D.E., Muller, G., Morel, E., Costes, B. and Henry, Y. (1996) Synthesis and Formulation of Novel Phosphorylated Flame Retardant Curatives for Thermoset Resins. Polymer Degradation and Stability, 54, 311-315. http://dx.doi.org/10.1016/S0141-3910(96)00056-0

[6] Cheng, K.-C., Yu, S.-Y. and Chiu, W.-Y. (2002) Thermal Properties of Side-Chain Phosphorus-Containing Epoxide Cured with Amine. Applied Polymer Science, 83, 2741-2748. http://dx.doi.org/10.1002/app.10161

[7] Kumar, S.A., Denchev, Z. and Alagar, M. (2006) Synthesis and Thermal Characterization of Phosphorus Containing Siliconized Epoxy Resins. European Polymer Journal, 42, 2419-2429. http://dx.doi.org/10.1016/j.eurpolymj.2006.06.010

[8] Wang, C.S. and Sheigh, J.Y. (1998) Synthesis and Properties of Epoxy Resin Containing 2-(6-Oxid-6H-Dibenzene (1,2) Oxaphosphorin-6-yl) 1,4-Benzenediol. Polymer, 39, 5819-5826. http://dx.doi.org/10.1016/S0032-3861(97)10292-0

[9] Hussain, M. and Simon, G.P. (2003) Fabrication of Phosphorus-Clay Polymer Nanocomposites for Fire Performance. Journal of Materials Science Letters, 22, 1471-1475. http://dx.doi.org/10.1023/A:1026186627407

[10] Kumar, S.A. and Narayanan, T.S.N.S. (2002) Thermal Properties of Siliconized Epoxy Interpenetrating Coatings. Progress in Organic Coatings, 45, 323. http://dx.doi.org/10.1016/S0300-9440(02)00062-0

[11] Mikroyannidis, J.A. and Kourtides, D.A. (1984) Curing of Epoxy Resins with 1-[Di(2-Chloroethoxyphosphinyl) Methyl]-2,4-and -2,6-Diaminobenzene. Journal of Applied Polymer Science, 29, 197-209. http://dx.doi.org/10.1002/app.1984.070290118

[12] Mikroyannidis, J.A. and Kourtides, D.A. (1984) Synthesis and Characterization of Phosphorus-Containing Polyamides and Copolyamides Based on 1 Methyl]-2,4- and -2,6-Diaminobenzenes. Advances in Chemistry, 208, 351. http://dx.doi.org/10.1021/ba-1984-0208.ch022

[13] Chin, W.K., Shau, M.D. and Tsai, W.C. (1995) Synthesis, Structure, and Thermal Properties of Epoxy-Imide Resin Cured by Phosphorylated Diamine. Journal of Polymer Science Part A: Polymer Chemistry, 33, 373-379. http://dx.doi.org/10.1002/pola.1995.080330304

[14] Maiti, S., Banerjee, S. and Palit, S.K. (1993) Phosphorus Containing Polymers (a Review). Progress in Polymer Science, 18, 217-261. http://dx.doi.org/10.1016/0079-6700(93)90026-9

[15] Weil, E.D., Levchik, S.V., Ravey, M. and Zhu, W. (1999) A Survey of Recent Progress in Phosphorus-Based Flame Retardants and Some Mode of Action Studies. Phosphorus, Sulfur, and Silicon and the Related Elements, 144, 17-20. http://dx.doi.org/10.1080/10426509908546171

[16] Jeng, R.J., Shau, S.M., Lin, J.J., Su, W.C. and Chiu, Y.S. (2002) Flame Retardant Epoxy Polymers Based on All Phosphorus-Containing Components. European Polymer Journal, 38, 683-693. http://dx.doi.org/10.1016/S0014-3057(01)00246-4

[17] Toldy, A., Toth, N., Anna, P. and Marosi, G. (2006) Synthesis of Phosphorus-Based Flame Retardant Systems and Their Use in an Epoxy Resin. Polymer Degradation and Stability, 91, 585-592. http://dx.doi.org/10.1016/j.polymdegradstab.2005.02.025

[18] Mauerer, O. (2005) New Reactive, Halogen-Free Flame Retardant System for Epoxy Resins. Polymer Degradation and Stability, 88, 70-73. http://dx.doi.org/10.1016/j.polymdegradstab.2004.01.027

[19] Liu, Y.L., Hsiue, G.H., Lee, R.H. and Chiu, Y.S. (1998) Phosphorus-Containing Epoxy for Flame Retardant. III: Using Phosphorylated Diamines as Curing Agents. Journal of Applied Polymer Science, 63, 895-901.

[20] Gowariker, V.R., Viswanathan, N.V. and Sreedhar, J. (1905) Polymer Science. John Wiley \& Sons Inc., Hoboken.

[21] Wang, H., Hoa, S.V. and Wood-Adams, P.M. (2006) New Method for the Synthesis of Clay/Epoxy Nanocomposites. Journal of Applied Polymer Science, 100, 4286-4296. http://dx.doi.org/10.1002/app.23859

[22] Troitzch, J. (1990) International Plastics Flammability Handbook. 2nd Edition.

[23] Van Krevelen, D.W. (1975) Some Basic Aspects of Flame Resistance of Polymeric Materials. Polymer, 16, 615-620. http://dx.doi.org/10.1016/0032-3861(75)90157-3

[24] Lin, C.H., Feng, C.C. and Hwang, T.Y. (2007) Preparation, Thermal Properties, Morphology, and Microstructure of Phosphorus-Containing Epoxy/SiO ${ }_{2}$ and Polyimide/SiO 2 Nanocomposites. European Polymer Journal, 43, 725-742. http://dx.doi.org/10.1016/j.eurpolymj.2006.12.030 